\title{
Improving Information on Maternal Medication Use by Linking Prescription Data to Congenital Anomaly Registers: A EUROmediCAT Study
}

\author{
Linda de Jonge ${ }^{1} \cdot$ Ester Garne $^{2} \cdot$ Rosa Gini $^{3} \cdot$ Susan E. Jordan ${ }^{4} \cdot$ Kari Klungsoyr $^{5,6}$ • \\ Maria Loane $^{7}$ - Amanda J. Neville ${ }^{8}$ Anna Pierini ${ }^{9,10}$ - Aurora Puccini ${ }^{11}$. \\ Daniel S. Thayer ${ }^{12} \cdot$ David Tucker $^{13} \cdot$ Anne Vinkel Hansen ${ }^{14} \cdot$ Marian K. Bakker ${ }^{1,15}$
}

Published online: 8 July 2015

(c) The Author(s) 2015. This article is published with open access at Springerlink.com

\begin{abstract}
Introduction Research on associations between medication use during pregnancy and congenital anomalies is significative for assessing the safe use of a medicine in pregnancy. Congenital anomaly (CA) registries do not have optimal information on medicine exposure, in contrast to prescription databases. Linkage of prescription databases to the CA registries is a potentially effective method of obtaining accurate information on medicine use in pregnancies and the risk of congenital anomalies.
\end{abstract}

A presentation was given at the 54th Annual Meeting of the Teratology Society in Washington, USA, 28 June-2 July 2014.

The abstract of the presentation has been published: De Jonge et al. [1].

Linda de Jonge

1.de.jonge@umcg.nl

1 Department of Genetics, University of Groningen, University Medical Center Groningen, Groningen, The Netherlands

2 Paediatric Department, Hospital Lillebaelt, Kolding, Denmark

3 Agenzia regionale di sanità della Toscana, Florence, Italy

4 College of Human and Health Sciences, Swansea University, Swansea, UK

5 Department of Global Public Health and Primary Care, University of Bergen, Bergen, Norway

6 Medical Birth Registry of Norway, Norwegian Institute of Public Health, Oslo, Norway

7 Institute of Nursing and Health Research, Ulster University, Newtownabbey, County Antrim, Northern Ireland, UK

8 Registro IMER-IMER Registry (Emila Romagna Registry of Birth Defects), Center for Clinical and Epidemiological Research, University of Ferrara, Ferrara, Italy
Methods We linked data from primary care and prescription databases to five European Surveillance of Congenital Anomalies (EUROCAT) CA registries. The linkage was evaluated by looking at linkage rate, characteristics of linked and non-linked cases, first trimester exposure rates for six groups of medicines according to the prescription data and information on medication use registered in the CA databases, and agreement of exposure.

Results Of the 52,619 cases registered in the CA databases, 26,552 could be linked. The linkage rate varied between registries over time and by type of birth. The first trimester exposure rates and the agreements between the databases varied for the different medicine groups. Information on anti-epileptic drugs and insulins and analogue medicine use recorded by CA registries was of good quality. For selective serotonin reuptake inhibitors, antiasthmatics, antibacterials for systemic use, and gonadotropins and other ovulation stimulants, the recorded information was less complete.

\section{Key Points}

Linkage of primary care or prescription databases to congenital anomaly (CA) registries improved the quality of information on maternal use of medicines in pregnancy.

The quality of information improved particularly for medicine groups that are less fully registered in CA registries, such as selective serotonin reuptake inhibitors, anti-asthmatics, antibacterials for systemic use, and gonadotropins and other ovulation stimulants. 
Conclusion Linkage of primary care or prescription databases to CA registries improved the quality of information on maternal use of medicines in pregnancy, especially for medicine groups that are less fully registered in CA registries.

\section{Introduction}

Medicines are commonly used during pregnancy: approximately $80 \%$ of all women use at least one medicine during pregnancy [2]. Although the use of some medicines is unavoidable for serious or chronic conditions, fetal exposure may increase the risk of a congenital anomaly (CA). One example is the anti-epileptic medication valproic acid, which increases the risk of having a child with spina bifida if taken in the first trimester of pregnancy [3]. However, little is known regarding the teratogenic effects of many medicines. Research on possible associations between medicine use during pregnancy and CAs is of great importance for assessing the safe use of a medicine in pregnancy. Since CAs are rare outcomes, and medicine needs to be analysed in specific groups or as specific drugs, we need to study large datasets with accurate and detailed information on the type and timing of medicine exposure in pregnancy and the type of a possibly related CA.

The European Surveillance of Congenital Anomalies (EUROCAT) network consists of 43 population-based registries set up for the epidemiological surveillance of CAs; the network covers $29 \%$ of all births in Europe [46]. These registries hold information on fetuses and children with CAs, and associated factors such as maternal medicine use in pregnancy. Most of the registries retrieve information on first-trimester maternal medicine use from medical files, which may be limited and incomplete [7].

Prescription databases, which are increasingly being used to explore associations between medicine use in pregnancy and CAs [8-11], contain more complete

9 Tuscany Registry of Congenital Defects (RTDC), Fondazione Toscana "Gabriele Monasterio", Pisa, Italy

10 Institute of Clinical Physiology, National Research Council (IFC-CNR), Pisa, Italy

11 Drug Policy Service, Emilia Romagna Regional Health Authority, Bologna, Italy

12 SAIL Databank, Swansea University, Swansea, UK

13 Public Health Wales, Singleton Hospital, Swansea, UK

14 Section of Social Medicine, Department of Public Health, University of Copenhagen, Copenhagen, Denmark

15 Department of Obstetrics and Gynaecology, University of Groningen, University Medical Center Groningen, Groningen, The Netherlands information on medicine use than CA registries, and prescribing information is prospectively collected. Given the quality of information on medicine exposure that is recorded in both CA registries and prescription databases, linking prescription databases to the EUROCAT CA registries is a potentially effective method of obtaining accurate information on medicine use in pregnancies that were complicated by fetal CA.

In this study we linked administrative prescription databases with five CA registries. We present the results for six selected groups of medicines: anti-epileptic medicines [Anatomical Therapeutic Chemical (ATC) code [12] N03A], insulins and analogues (A10A), selective serotonin reuptake inhibitors (SSRIs) (N06AB), anti-asthmatics (R03), antibacterials for systemic use (J01), and gonadotropins and other ovulation stimulants (G03G).

This research was embedded in the EUROmediCAT project [13], which stimulates the collaboration of healthcare databases and EUROCAT registries. EUROmediCAT is a Seventh Framework Programme study funded by the European Union.

\section{Methods}

In this study, prescription/primary care databases were linked to five EUROCAT CA registries:

- Wales: the general practitioner (GP) data in the Secure Anonymised Information Linkage (SAIL) Databank $[14,15]$ was linked to the Welsh CA registry [Congenital Anomaly Register and Information Service (CARIS)];

- Norway: Reseptregisteret [Norwegian Prescription Database (NorPD)] was linked to the Medical Birth Registry from Norway (MBRN) [16, 17];

- Odense, Denmark: Laegemiddelstatistikregisteret (Danish National Prescription Registry) [18] was linked to the CA registry of Odense, Denmark;

- Emilia Romagna, Italy: Emilia Romagna Prescription Database (ERPD) [19] was linked to Emilia Romagna CA registry (IMER), Italy;

- Tuscany, Italy: Assistenza Farmaceutica Territoriale (AFT; Pharmaceutical Territorial Assistance) and Farmaci a Erogazione Diretta (FED; Medicine Directly Dispensed by the Health System) [20] were linked to the CA registry of Tuscany, Italy (RTDC; Tuscan Registry of Congenital Defects).

The CA registries collect data on fetuses and infants with CAs, including live births (LB), fetal deaths (FDs) $\geq 20$ weeks of gestational age (including stillbirths) and terminations of pregnancy for fetal anomaly (TOPFA). Information on date of birth, gestational age at birth, 
maternal age, long-term diseases, maternal medicines and disease exposures during pregnancy are also collected. The first trimester of pregnancy is defined according to the EUROCAT Guide [21] as the period from the first day of the last menstrual period (LMP) up to 12 completed weeks of gestation (day 0 to day 83).

The primary care or prescription databases involved in our linkage effort are population-based administrative databases that contain data on medicines prescribed and/or dispensed. In the linked prescription data, the first trimester was defined as the period from the first day of the LMP as recorded in the CA database up to 14 completed weeks of gestation (day 0 to day 97). If the LMP was unknown, it was calculated as the date of birth of the child minus the gestational age at birth as recorded in the CA database. If the gestational age at birth was unknown, a standardised length of 280 days (40 weeks) for live births and 224 days (32 weeks) for still births was used. If the gestational age was unknown for a TOPFA case, the average age for TOPFAs for the respective registry across the whole of the included time period was used. Characteristics of the primary care/prescription databases and the $\mathrm{CA}$ registries have been described in detail elsewhere [5, 7, 22, 23]. Table 1 summarises the birth years, the number of CA cases registered in the study period, the registry sources for maternal medicine use, whether the medicine recorded in the CA data was based on the first trimester only or for the whole pregnancy and the proportion of cases with at least one medicine recorded in the CA database.

We applied a distributed database model, in which the linkage was performed locally for all registries and the linked datasets were kept locally [24]. The linkage was performed by matching identification numbers and/or maternal characteristics in both the primary care/prescription and the CA databases. For CA cases identified in the primary care/prescription databases, the information held on medicine use was added to the information in the CA registry. Details of the linkage process have been described elsewhere [25].

An Access ${ }^{\circledR}$-based software module, the Linkage Data Management Program (LDMP), was developed for this project and used to ensure validated datasets. The LDMP was used to import and export data, validate data, and generate tables for evaluation and analyses. The use of the LDMP ensured the compatibility of anomaly subgroups and medicine groups among the participating registries and allowed tables to be generated in a uniform way. To evaluate the linkage effort, the participating registries provided tables generated by LDMP. Since the Danish regulations do not allow external software to be used on their server, Odense, Denmark was not able to import their data via the LDMP. They generated the aggregated tables locally and generated the tables manually, using the same selection criteria and definitions as in the LDMP.

In the analyses, cases that met the EUROCAT case definition were included: cases with major CA defined by the Q-chapter of the International Classification of Diseases, 10th revision (ICD-10), or in the range 740-759 of the International Classification of Diseases, 9th revision (ICD-9), and a very limited set of conditions not included in the Q chapter [21]. Cases with isolated minor anomalies were excluded from the EUROCAT case definition.

Using the LDMP, each registry evaluated the linkage on the following aspects:

- Linkage success: defined as the proportion of cases in the CA database that could be linked to the primary care/prescription data.

- Comparison of the linked and non-linked cases: since not all the cases could be linked, we considered it relevant to compare both groups on year of birth and type of birth. A Chi-squared $\left(\chi^{2}\right)$ test was performed for both factors to determine the statistical significance. If $20 \%$ of the cells in the contingency table had less than five observations, a Fisher Exact test was performed instead of the $\chi^{2}$ test. The statistical tests were performed in PASWStatistics 22 (IBM SPSS Statistics for Windows, Version 22.0. IBM Corp., Armonk, NY).

- Comparison of data on first trimester medicine use: the 'first trimester exposures rates' and the 'agreement of exposure' were calculated as described in Table 2 to compare the data. These factors were calculated for six groups of medicines: anti-epileptic medicines, insulins and analogues, SSRIs, anti-asthmatics, antibacterials for systemic use, and gonadotropins and other ovulation stimulants. The agreement according to the primary care/prescription data may be influenced by the definition of first trimester exposure (date of prescription in the period 0-97 days); therefore, we also calculated the agreement using a broader first-trimester definition (31 to +97 days after the LMP).

\section{Results}

The five CA databases included 52,619 cases in total, of which $65.7 \%$ ( $n=34,547)$ could be linked. The proportion of cases that could be linked ranged from $31.7 \%$ in Wales (where $40 \%$ of the primary care practices contribute prescription data to the voluntary SAIL database) to $100 \%$ in Odense, Denmark. Of the 34,547 registered cases that were linked to prescription databases, 26,552 (76.9\%) met the EUROCAT case definition as described in Sect. 2 (Table 3). 
Table 1 Summary of birth years, number of cases and the sources of information on maternal medicine use per registry

\begin{tabular}{|c|c|c|c|c|c|}
\hline & Wales & Norway & $\begin{array}{l}\text { Odense, } \\
\text { Denmark }\end{array}$ & Emilia Romagna & Tuscany \\
\hline Birth years included in the linkage & 1998-2010 & 2004-2010 & 1998-2010 & 2004-2010 & 2003-2010 \\
\hline Number of cases registered in study period & 17,244 & 21,136 & 2006 & 6410 & 5823 \\
\hline $\begin{array}{l}\text { Sources for maternal use of medicines used } \\
\text { by the congenital anomalies registry [7] }\end{array}$ & $\begin{array}{l}\text { Medical files } \\
\text { from: } \\
\text { Healthcare } \\
\text { providers in } \\
\text { relation to } \\
\text { pregnancy }\end{array}$ & $\begin{array}{l}\text { Medical files } \\
\text { from: } \\
\text { Healthcare } \\
\text { providers in } \\
\text { relation to } \\
\text { pregnancy } \\
\text { Healthcare } \\
\text { providers of } \\
\text { the child }\end{array}$ & $\begin{array}{l}\text { Medical files } \\
\text { from: } \\
\text { Healthcare } \\
\text { providers in } \\
\text { relation to } \\
\text { pregnancy } \\
\text { Healthcare } \\
\text { providers of } \\
\text { the child }\end{array}$ & $\begin{array}{l}\text { Medical files from: } \\
\text { Healthcare providers in } \\
\text { relation to pregnancy } \\
\text { Healthcare providers of } \\
\text { the child } \\
\text { Healthcare providers } \\
\text { not in relation to } \\
\text { pregnancy } \\
\text { (prescription data) }\end{array}$ & Questionnaire \\
\hline $\begin{array}{l}\text { Period of medicine use recorded in } \\
\text { congenital anomalies data [7] }\end{array}$ & 1st trimester & $\begin{array}{l}\text { Whole } \\
\text { pregnancy }\end{array}$ & 1st trimester & Whole pregnancy & 1st trimester \\
\hline $\begin{array}{l}\text { Proportion of cases with at least one } \\
\text { medication, including vitamins and } \\
\text { minerals, recorded for the years } \\
\text { 2004-2010 [7] }\end{array}$ & $15.6 \%$ & $22.4 \%$ & $17.7 \%$ & $33.8 \%$ & $13.2 \%$ \\
\hline
\end{tabular}

CARIS Congenital Anomaly Register and Information Service, MBRN Medical Birth Registry from Norway, RTDC Tuscan Registry of Congenital Defects

Table 2 Data in the primary care/prescription databases and the congenital anomaly databases

\begin{tabular}{llll}
\hline CA database & \multicolumn{3}{l}{ Prescription database } \\
\cline { 2 - 4 } & + & - & Total \\
\hline+ & $\mathrm{A}$ & $\mathrm{B}$ & $\mathrm{A}+\mathrm{B}$ \\
- & $\mathrm{C}$ & $\mathrm{D}$ & $\mathrm{C}+\mathrm{D}$ \\
Total & $\mathrm{A}+\mathrm{C}$ & $\mathrm{B}+\mathrm{D}$ & $\mathrm{A}+\mathrm{B}+\mathrm{C}+\mathrm{D}$
\end{tabular}

First trimester exposure rate according to $\mathrm{CA}$ registry data: \% of women exposed to medicine in the first trimester according to the CA registry

$(\mathrm{A}+\mathrm{B}) /(\mathrm{A}+\mathrm{B}+\mathrm{C}+\mathrm{D}) \times 100 \%$

First trimester exposure rate according to prescription data: $\%$ of women exposed to medicine in the first trimester according to the prescription database

$(\mathrm{A}+\mathrm{C}) /(\mathrm{A}+\mathrm{B}+\mathrm{C}+\mathrm{D}) \times 100 \%$

Agreement of exposure according to the primary care/prescription data: Number of women using medicine according to both CA registry and prescription database divided by the total number of women with medicine prescribed in the prescription database

$\mathrm{A} /(\mathrm{A}+\mathrm{C}) \times 100 \%$

Agreement of exposure according to the CA data: Number of women using medicine according to both CA registry and prescription database divided by the total number of women with medicine prescribed in the CA registry

$\mathrm{A} /(\mathrm{A}+\mathrm{B}) \times 100 \%$

The numbers per registry for each medicine are available at http:// www.euromedicat.eu/content/WP3\%20Deliverable\%2011\%20Report. pdf

$C A$ congenital anomaly
The linked and non-linked EUROCAT cases were compared for year of birth and type of birth for the registries with less than $100 \%$ linkage success (Table 4). There was a significant difference between the linked and non-linked cases for all registries in year of birth. For Wales, Emilia Romagna and Tuscany, the rate of linked cases increased over time, while the number of linked cases decreased over time in Norway. For type of birth, there were no differences between linked and non-linked cases for Wales and Norway. For Emilia Romagna, TOPFA cases were only seen in the non-linked group, while for Tuscany there were fewer live births (74.0 vs. $86.2 \%)$ but more TOPFA cases (25.1 vs. $12.6 \%$ ) in the linked group.

The first trimester exposure rates according to the CA data and the primary care/prescription database are shown in Table 5. For the anti-epileptic medicines and the insulins and analogues, there were small, but potentially clinically important, differences between the first trimester exposure rates based on the $\mathrm{CA}$ registries and the primary care or prescription database. The first trimester exposure rates for anti-asthmatics also revealed small differences between those recorded in the $\mathrm{CA}$ registries and in the primary care or prescription database per registry, except for Tuscany. For Tuscany, the first trimester exposure rate recorded in the prescription database was more than six times higher than the rate recorded in the CA registry. For the SSRIs, the first trimester exposure rates recorded in the primary care or prescription database were two to three times higher 
Table 3 Linkage results per registry

\begin{tabular}{|c|c|c|c|c|c|}
\hline Registry & $\begin{array}{l}\text { Wales, } \\
n(\%)\end{array}$ & $\begin{array}{l}\text { Norway, } \\
n(\%)\end{array}$ & $\begin{array}{l}\text { Odense, } \\
\text { Denmark, } \\
n(\%)\end{array}$ & $\begin{array}{l}\text { Emilia } \\
\text { Romagna, } \\
n(\%)\end{array}$ & $\begin{array}{l}\text { Tuscany, } \\
n(\%)\end{array}$ \\
\hline Years of inclusion & $1998-2010$ & 2004-2010 & $1998-2010$ & 2004-2010 & $2003-2010$ \\
\hline Total number of cases in CA registry & $17,244(100)$ & $21,136(100)$ & $2006(100)$ & $6410(100)$ & $5823(100)$ \\
\hline Linked to prescription/primary care database & $5472(31.7)$ & $20,874(98.8)$ & $2006(100)$ & $3172(49.5)$ & $3023(51.9)$ \\
\hline $\begin{array}{l}\text { Total number of EUROCAT cases }{ }^{\mathrm{a}} \text { linked to prescription } \\
\text { database (\% calculated on linked cases) }\end{array}$ & $5322(97.3)$ & $13,474(64.5)$ & $2006(100)$ & $3034(95.6)$ & $2716(89.8)$ \\
\hline
\end{tabular}

CA congenital abnormality, CARIS Congenital Anomaly Register and Information Service, EUROCAT European Surveillance of Congenital Anomalies, MBRN Medical Birth Registry from Norway, RTDC Tuscan Registry of Congenital Defects

${ }^{a}$ A EUROCAT case is defined as a child with major CA defined by the Q chapter of the International Classification of Diseases, 10th edition (ICD-10), or in the range 740-759 of the International Classification of Diseases, 9th edition (ICD-9), and a very limited set of conditions not included in the Q chapter [23]. Cases with only minor anomalies were excluded from the EUROCAT case definition

than the rates recorded in the CA registries for Wales, Emilia Romagna and Tuscany. For antibacterials for systemic use, the first trimester exposure rates recorded in the primary care or prescription databases was much higher than the rates in the CA registries. Furthermore, there was a wide variation over the registries: for the $\mathrm{CA}$ registries, the rates ranged from $1.84 \%$ (Tuscany) to $10.12 \%$ (Emilia Romagna), while for the primary care or prescription databases the rates ranged from $9.84 \%$ (Norway) to $15.52 \%$ (Emilia Romagna). The first trimester exposure rates for the gonadotropins and other ovulation stimulants were also higher in the prescription databases, except for Wales.

The agreement according to the primary care/prescription data and the agreement according to the CA data for the first trimester is shown in Table 6. For the anti-epileptic medicines and insulins and analogues, which are both used for long-term conditions, the agreement between both databases was generally relatively high. The SSRIs and anti-asthmatics, which are also used in long-term conditions, showed a lower agreement between the two databases. Medicines for occasional use, such as antibacterials for systemic use and gonadotropins and other ovulation stimulants, showed a relatively low agreement between the databases. Extending the time period by including the month before the first trimester did not affect the findings on anti-epileptic medicines and insulins and analogues to a large extent, but the agreement according to the CA data was increased for SSRIs and anti-asthmatics for some of the registries (Table 7).

\section{Discussion}

We linked administrative databases to five CA registries and evaluated the results of the linkage for six types of common medicines. The linkage success varied between registries over time and, for the Italian registries, by type of birth. The first trimester exposure rates and the agreements between the databases varied for the different medicine groups. In general, information on anti-epileptic medicines and insulins and analogue medicine use recorded by CA registries was of good quality. For SSRIs, anti-asthmatics, antibacterials for systemic use, and gonadotropins and other ovulation stimulants, the recorded information was less complete.

A major challenge in using prescription data is linking it to all the cases of CAs, irrespective of pregnancy outcome. For Norway and Odense, Denmark, linkage was possible for most cases, as the linkage used personal identification (ID) numbers, while the linkage success was lower for the other registries. In Wales, GPs contribute to SAIL on a voluntary basis; currently, $40 \%$ of the GPs contribute and, although this percentage is increasing, it reduces the number of Welsh cases that could be linked. For Emilia Romagna, the TOPFA cases could not be included in the linkage because the CA registry does not have ID numbers for the TOPFA cases or their mothers due to privacy regulations. As a result, the linked cases are biased towards the less severe cases there. In Tuscany, an ID number for the mother was only available for $52 \%$ of the TOPFA cases. Therefore, one should be aware that if not all cases can be linked, there may be some bias in the results reported or the linked dataset may not be suitable to analyse a possible association between medication use and severe anomalies that result frequently in terminations of pregnancy.

Medicines prescribed or dispensed before the first trimester were not included in the first trimester definition of the primary care or prescription databases. It is possible that these medicines, although prescribed earlier, were also taken in the first trimester and therefore registered in the CA registry. Technically, there is a difference in the definition of the first trimester between the primary care or prescription databases and the CA registries. However, we 


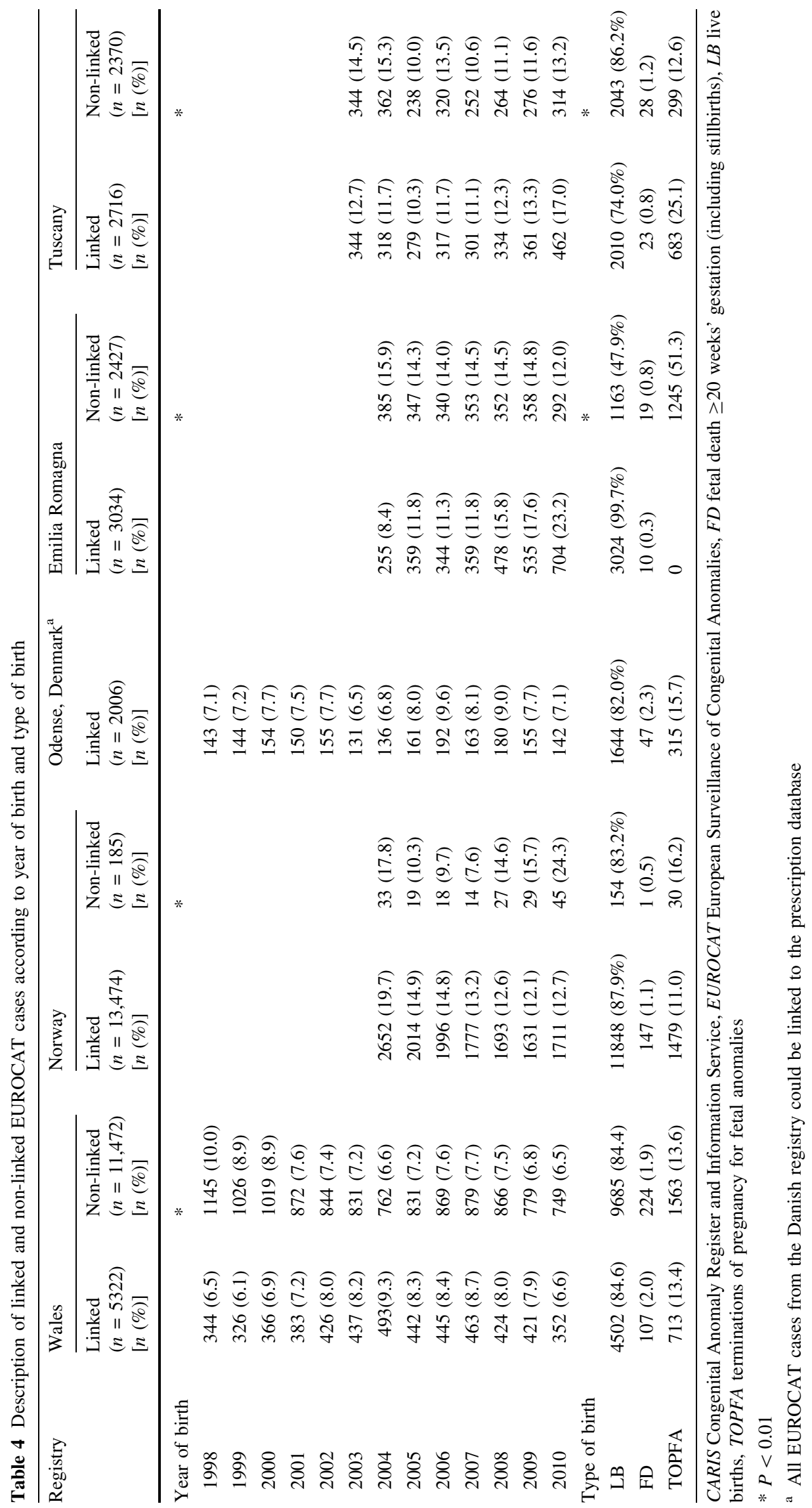


Table 5 First trimester exposure rates for congenital abnormality data and the primary care/prescription data for Wales, Norway, Odense, Denmark, Emilia Romagna, and Tuscany (\%)

\begin{tabular}{|c|c|c|c|c|c|c|c|c|c|c|c|}
\hline \multirow[t]{2}{*}{ Medicine subgroup (EUROmediCAT) } & \multirow[t]{2}{*}{ ATC code starting with } & \multicolumn{2}{|l|}{ Wales } & \multicolumn{2}{|c|}{ Norway } & \multicolumn{2}{|c|}{$\begin{array}{l}\text { Odense, } \\
\text { Denmark }\end{array}$} & \multicolumn{2}{|c|}{$\begin{array}{l}\text { Emilia } \\
\text { Romagna }\end{array}$} & \multicolumn{2}{|c|}{ Tuscany } \\
\hline & & $\mathrm{CA}$ & $\operatorname{PrX}$ & $\mathrm{CA}$ & $\operatorname{PrX}$ & $\mathrm{CA}$ & $\operatorname{PrX}$ & $\mathrm{CA}$ & $\operatorname{PrX}$ & $\mathrm{CA}$ & $\operatorname{PrX}$ \\
\hline Years of inclusion & & $1998-$ & -2010 & 2004 & -2010 & 1998 & -2010 & $2004-2$ & 010 & 2003 & -2010 \\
\hline Number of cases & & 5322 & & 13,47 & & 2006 & & 3034 & & 2716 & \\
\hline Anti-epileptics & N03A & 0.77 & 0.66 & 0.46 & 0.50 & 0.55 & 0.60 & 0.26 & 0.33 & 0.59 & 0.52 \\
\hline Insulins and analogues & $\mathrm{A} 10 \mathrm{~A}$ & 1.01 & 0.70 & 1.25 & 0.91 & 0.65 & 0.70 & 0.43 & 0.36 & 0.70 & 0.37 \\
\hline Anti-asthmatics & R03 & 4.47 & 5.58 & 1.74 & 1.89 & 3.14 & 3.24 & 2.11 & 2.74 & 0.37 & 2.39 \\
\hline SSRIs & N06AB & 1.05 & 3.44 & 0.62 & 0.79 & 1.65 & 1.74 & 0.33 & 0.69 & 0.41 & 1.44 \\
\hline Antibacterials for systemic use & $\mathrm{J} 01$ & 2.87 & 12.78 & 6.43 & 9.84 & - & - & 10.12 & 15.52 & 1.84 & 12.96 \\
\hline $\begin{array}{l}\text { Gonadotropins and other ovulation } \\
\text { stimulants }\end{array}$ & G03G & 1.16 & 0.34 & 0.10 & 3.03 & - & - & 0.69 & 1.05 & 0.07 & 1.58 \\
\hline
\end{tabular}

ATC Anatomical Therapeutic Chemical, CA congenital anomaly registry, $\operatorname{Pr} X$ prescription or primary care database, SSRIs selective serotonin reuptake inhibitors, - indicates data were not retrieved

Table 6 Comparison of parameters based on the first trimester (day 0 to day 97)

\begin{tabular}{|c|c|c|c|c|c|c|c|c|c|c|c|}
\hline \multirow[t]{2}{*}{$\begin{array}{l}\text { Medicine subgroup } \\
\text { (EUROmediCAT) }\end{array}$} & \multirow{2}{*}{$\begin{array}{l}\text { ATC code } \\
\text { starting } \\
\text { with }\end{array}$} & \multicolumn{5}{|c|}{$\begin{array}{l}\text { Agreement according to the prescription/primary } \\
\text { care data }(\%)\end{array}$} & \multicolumn{5}{|c|}{ Agreement according to the CA data (\%) } \\
\hline & & Wales & Norway & $\begin{array}{l}\text { Odense, } \\
\text { Denmark }\end{array}$ & $\begin{array}{l}\text { Emilia } \\
\text { Romagna }\end{array}$ & Tuscany & Wales & Norway & $\begin{array}{l}\text { Odense, } \\
\text { Denmark }\end{array}$ & $\begin{array}{l}\text { Emilia } \\
\text { Romagna }\end{array}$ & Tuscany \\
\hline Anti-epileptics & N03A & 77.1 & 63.2 & 91.7 & 40.0 & 71.4 & 65.9 & 69.4 & 100.0 & 50.0 & 62.5 \\
\hline $\begin{array}{c}\text { Insulins and } \\
\text { analogues }\end{array}$ & A10A & 81.1 & 71.5 & 71.4 & 63.6 & 60.0 & 55.6 & 52.4 & 76.9 & 53.8 & 31.6 \\
\hline Anti-asthmatics & R03 & 33.3 & 33.5 & 58.5 & 19.3 & 6.2 & 41.6 & 36.3 & 60.3 & 25.0 & 40.0 \\
\hline SSRIs & N06AB & 22.4 & 38.3 & 74.3 & 19.0 & 17.9 & 73.2 & 48.8 & 78.8 & 40.0 & 63.6 \\
\hline $\begin{array}{l}\text { Antibacterials for } \\
\text { systemic use }\end{array}$ & J01 & 7.8 & 16.4 & - & 27.8 & 6.3 & 34.6 & 25.2 & - & 42.7 & 44.0 \\
\hline $\begin{array}{l}\text { Gonadotropins and } \\
\text { other ovulation } \\
\text { stimulants }\end{array}$ & G03G & 27.8 & 1.5 & - & 21.9 & 2.3 & 8.1 & 42.9 & - & 33.3 & 50.0 \\
\hline
\end{tabular}

$\overline{A T C}$ Anatomical Therapeutic Chemical, CA congenital anomaly, SSRIs selective serotonin reuptake inhibitors, - indicates data were not retrieved

expect the influence on the first trimester exposure rates to be minimal, since the $\mathrm{CA}$ registries collect information on medicine use mainly from medical files (except Tuscany) in which medicine use is recorded as 'used in the first trimester' rather than on a specific date. In addition, the Norwegian CA registry and Emilia Romagna include information on medicine used during any time in pregnancy, not specifically during the first trimester. Therefore, misclassification of exposure cannot be ruled out; in particular, for medicines prescribed or taken at the start or towards the end of the first trimester, there may be disagreement between the information recorded in the CA data and the prescription data.

For Emilia Romagna, relatively low rates of agreement were found for medicines taken for long-term conditions.
The registry has now changed their data sources for medicine exposures and has added prescription information as a data source.

In general, per registry, the anti-epileptic medicines and insulins and analogues showed small differences between the first trimester exposure rates recorded in the CA registries and the rates in the primary care or prescription databases. In addition, the agreements between the primary care/prescription databases and the CA registries were, in general, relatively high. This was expected, since these medicines are prescribed for long-term conditions and used on a regular, daily basis; they are therefore well-recorded in both medical files and prescription databases. However, we noted 98 cases in which insulin (54) and anti-epileptics (44) were recorded as prescribed in primary care or 
Table 7 Comparison of parameters based on the broad definition of the first trimester (day -31 to day 97)

\begin{tabular}{|c|c|c|c|c|c|c|c|c|c|c|c|}
\hline \multirow[t]{2}{*}{$\begin{array}{l}\text { Medicine subgroup } \\
\text { (EUROmediCAT) }\end{array}$} & \multirow{2}{*}{$\begin{array}{l}\text { ATC code } \\
\text { starting } \\
\text { with }\end{array}$} & \multicolumn{5}{|c|}{$\begin{array}{l}\text { Agreement according to the prescription/primary } \\
\text { care data }(\%)\end{array}$} & \multicolumn{5}{|c|}{ Agreement according to the CA data $(\%)$} \\
\hline & & Wales & Norway & $\begin{array}{l}\text { Odense, } \\
\text { Denmark }\end{array}$ & $\begin{array}{l}\text { Emilia } \\
\text { Romagna }\end{array}$ & Tuscany & Wales & Norway & $\begin{array}{l}\text { Odense, } \\
\text { Denmark }\end{array}$ & $\begin{array}{l}\text { Emilia } \\
\text { Romagna }\end{array}$ & Tuscany \\
\hline Anti-epileptics & N03A & 76.9 & 58.2 & 91.7 & 30.8 & 62.5 & 73.2 & 74.2 & 100 & 50 & 62.5 \\
\hline $\begin{array}{c}\text { Insulins and } \\
\text { analogues }\end{array}$ & A10A & 82.1 & 72.3 & 71.4 & 63.6 & 63.6 & 59.3 & 56.0 & 76.9 & 53.8 & 36.8 \\
\hline Anti-asthmatics & R03 & 33.8 & 30.7 & 58.9 & 22.6 & 5.0 & 47.9 & 40.6 & 68.3 & 40.6 & 40.0 \\
\hline SSRIs & N06AB & 18.2 & 35.3 & 73.0 & 19.4 & 16.3 & 76.8 & 58.3 & 81.8 & 60.0 & 72.7 \\
\hline $\begin{array}{l}\text { Antibacterials for } \\
\text { systemic use }\end{array}$ & J01 & 7.5 & 15.1 & - & 26.7 & 5.1 & 42.5 & 28.8 & - & 52.4 & 46 \\
\hline $\begin{array}{l}\text { Gonadotropins and } \\
\text { other ovulation } \\
\text { stimulants }\end{array}$ & G03G & 36.1 & 1.7 & - & 22.4 & 2.6 & 21.0 & 64.3 & - & 71.4 & 100 \\
\hline
\end{tabular}

ATC Anatomical Therapeutic Chemical, CA congenital anomaly, SSRIs selective serotonin reuptake inhibitors, - indicates data were not retrieved

prescription databases, but not recorded in or abstracted from the medical files, which are the main data source for the CA registries. Such omissions from the medical records could have serious clinical consequences, unless more accurate histories were taken on admission for delivery.

For the anti-asthmatics, small differences were found between the first-trimester exposure rates recorded in the CA registries and the primary care or prescription database per registry. However, the agreements between the primary care/prescription databases and the CA registries were, in general, relatively low. The most plausible explanation for this is that some anti-asthmatics are often taken 'as necessary'. It is possible that they were dispensed before the first trimester, and were therefore not present in the prescription database as a first-trimester prescription, but that they were indeed used in the first trimester and therefore recorded in the CA registry. Extending the relevant period to include the month before pregnancy increased the agreement for anti-asthmatics and SSRIs. This emphasises that the timeframe used in the definition of the first trimester may differ for medicines depending on prescribing characteristics. Other explanations for low agreement could be that the prescribed medicines were not taken (noncompliance) or that the medicines were taken but their use was not recorded. Medicines may not be recorded in medical files for several reasons: women may forget; the midwife may not ask the woman about medicine use when taking the initial medical history, or the question may be asked in a perfunctory manner, so that the woman does not realise the importance of an accurate medical history; women may be uncertain of the starting date of their first trimester; medication use may be mentioned but not recorded in the medical file; or the medicine was prescribed after the first antenatal visit and therefore not recorded in the medical file. Some CA registry records did not give the full name of the medicines taken, so no ATC code could be matched to the prescription database: for example, if the woman cannot name her specific medicine, just 'taking antidepressant' may be recorded. When no information is found in medical records on maternal medication use, registries may either interpret this as 'no medication taken' or 'medication use unknown'. The use of administrative data may overcome this problem.

For the SSRIs, the first trimester exposure rates recorded in the primary or prescription database were two to three times higher than the rates recorded in some CA registries. Furthermore, SSRIs had a relatively low agreement according to the primary care/prescription data. The high rate of non-reporting of antidepressants suggests that records might be biased by the stigma surrounding mental illness. This may lead to either non-adherence with prescribed regimens or non-reporting. Reporting of antiepileptic prescriptions (often for mental illness) may have been similarly affected.

For the antibacterials for systemic use, the rates found in the primary care or prescription databases were much higher than the rates in CA registries and there were differences between the registries. The agreements according to both the primary care/prescription databases and the CA registries were, in general, relatively low. It is likely that, by the time of their interviews with the midwife, some women had forgotten having a short course of antibacterial agents. The differences across the registries can be explained by differences in the prescribing behaviour seen between the regions.

For gonadotropins and other ovulation stimulants, rates in the primary care or prescription databases were generally higher than the rates in CA registries, whereas the 
agreements according to both the primary care/prescription database and the $\mathrm{CA}$ registries were, in general, relatively low. Since these medicines are used in fertility treatments and the prevention of miscarriages, non-compliance is a less plausible explanation. The medicines were presumably used but not recorded. For gonadotropins and other ovulation stimulants, it is also possible that the woman did not mention their use because she did not consider them as medicines, or she was concerned about possible stigmatisation.

In conclusion, we found that information on antiepileptics and insulins and analogues was fairly complete in the CA registries, whereas for SSRIs, anti-asthmatics, antibacterials for systemic use, and gonadotropins and other ovulation stimulants, the information was less complete. Therefore, the linkage held more added value for SSRIs, anti-asthmatics, antibacterials for systemic use, and gonadotropins and other ovulation stimulants.

In our project, the linkage was performed locally for all registries and the linked datasets were kept locally, according to the distributed database model. This was necessary to comply with confidentiality regulations in Odense, Denmark, Norway and Wales, where linked data may not be sent outside the server. However, since large datasets are needed to study the safety of medicine use in pregnancy, the separate local datasets need to be combined for further studies on the risk of medicines in pregnancy; the ideal situation would be to collect and analyse such linked data in a central unit.

For this project we used data from prescription databases. In principle, prescription data contain the complete, prospectively recorded, medication history, except for over-the-counter medication and medications dispensed in hospitals and private clinics. However, in Norway the prescription database includes medicines dispensed to an individual who collects them at a hospital pharmacy (outpatient), but it does not include medicines given to individuals who are in hospital (inpatients). Furthermore, the quality of prescription data is not affected by the woman's recall or the accuracy of healthcare professionals who record medication use in medical files.

Nonetheless, this does not necessarily mean that medicines prescribed or dispensed are actually taken [26]. However, we know from a Dutch cross-sectional study that prescription data will most likely overestimate the exposure, but this overestimation seems to be minimal, which makes prescription records a reliable source for research into associations between medication use in pregnancy and CA [27].

The information on amount and dosage prescribed was not available in a standard way (defined daily dose) in the studied databases. Therefore, we could not include the duration of the prescription in our definition of exposure
[22]. To improve the use of prescription data, information on the amount prescribed and the daily dose should be included in the administrative databases. In addition, more uniformity concerning data definitions (ATC codes, medication grouping, first trimester definition) should also be taken into account to prevent bias.

In a previous Norwegian study, data of the NorPD and MBRN, which were also included in this study, were linked and compared by calculating the sensitivity, the specificity and the positive predictive value (PPV) of recorded medicine in the MBRN for the period 2004-2007, using NorPD as the 'gold standard' [16]. It was possible to compare the Norwegian study's 'sensitivity values' to our values of agreement according to the prescription database, and to compare the 'PPV values' to our values of agreement according to the CA registry. However, the Norwegian study did not provide data on gonadotropins and other ovulation stimulants specifically, while they did provide data on selective $\beta_{2^{-}}$ adrenoreceptor agonists (ATC code R03AC) and glucocorticoids (ATC code R03BA) instead of anti-asthmatics in general (ATC code R03). We found the values of sensitivity and the agreement according to the prescription data for Norway to be comparable. However, the values of the PPV were higher in the Norwegian study than the values we calculated for the agreement according to the CA registry for Norway. This difference may be related to the fact that the Norwegian study included all deliveries, while we only included deliveries with a CA in the offspring.

In another study, administrative data relating to all pregnancy events (which were classified as a birth, an ectopic pregnancy or a termination of pregnancy) in Western Australia were linked to a national database of dispensed medicines for the period 2002-2005. This study had a high linkage rate of health and other data due to very few missed links $(0.11 \%)$ and low permanent migration $(2.7 \%)$, and the researchers found that a medicine had been dispensed to $28.0 \%$ of women who had a pregnancy event [28, 29].

\section{Conclusion}

We have described the linkage of primary care or prescription databases to $\mathrm{CA}$ registries and shown that this improves the quality of information on maternal use of medicines in pregnancy, especially for some medicine groups that are less fully registered in CA registries, such as SSRIs, anti-asthmatics, antibacterials for systemic use, and gonadotropins and other ovulation stimulants. However, if the prescribed medicine is not actually taken, the use of prescription data may lead to an overestimation of exposure. Possible selection bias towards specific types of $\mathrm{CA}$ in the linked cases needs further attention. 
Acknowledgments This study uses anonymised data held in the Secure Anonymised Information Linkage (SAIL) system, which is part of the Welsh e-health records research infrastructure. We thank all the data providers who made anonymised data available for research

We also thank J. L. Senior of the department of Genetics of the University Medical Center Groningen for editorial assistance.

The results are also described in three deliverables which can be found at http://euromedicat.eu/content/Deliverable-11-WP3-ECASSystem.pdf (deliverable 11); http://euromedicat.eu/content/ Deliverable-12-WP3-ECAS-System.pdf (deliverable 12); and http:// euromedicat.eu/content/Deliverable-13-WP3-ECAS-System.pdf (deliverable 13).

The Tuscany Registry of Birth Defects is funded by the 'Direzione Generale Diritti di cittadinanza e coesione sociale - Regione Toscana'

\section{Compliance with ethical standards}

Funding This study was embedded in the EUROmediCAT project (http://www.euromedicat.eu), a Seventh Framework Programme study funded by the European Union.

Conflict of interest Rosa Gini performed a study with an unconditional grant from Eli-Lilly in 2014. Daniel S. Thayer has led a team for the SAIL Databank that has received funding from pharmaceutical company Janssen to perform analysis on an unrelated project.Linda de Jonge, Ester Garne, Susan E. Jordan, Kari Klungsoyr, Maria Loane, Amanda J. Neville, Anna Pierini, Aurora Puccini, David Tucker, Anne Vinkel Hansen and Marian K. Bakker have no conflicts of interest that are relevant to the content of this study.

Ethical approval Ethical approval was obtained in Wales for the linkage of the Secure Anonymised Information Linkage (SAIL) database to the Congenital Anomaly Register and Information Service (CARIS) and in Norway for linkage of the Norwegian Prescription database to the Medical Birth Registry Norway. The linkage in Denmark, Emilia Romagna and Tuscany could be performed without ethical approval.

Contribution to authorship L. de Jonge was responsible for study design, statistical analysis, interpreting the findings and writing the manuscript. E. Garne, R. Gini, S. E. Jordan, K. Klungsoyr, M. Loane, A. J. Neville, A. Pierini, A. Puccini, D. S. Thayer, F. D. Tucker and A. Vinkel Hansen contributed to all revisions of the manuscript. M. K. Bakker was responsible for supervising the study and contributed to all revisions of the manuscript.

Open Access This article is distributed under the terms of the Creative Commons Attribution-NonCommercial 4.0 International License (http://creativecommons.org/licenses/by-nc/4.0/), which permits any noncommercial use, distribution, and reproduction in any medium, provided you give appropriate credit to the original author(s) and the source, provide a link to the Creative Commons license, and indicate if changes were made.

\section{References}

1. De Jonge L, Jordan S, Tucker D, Thayer D, Pierini A, Gini R, et al. Linkage of prescription data to congenital anomaly registers to improve information on maternal medication use: a EUROmediCAT study [abstract]. Birth Defects Res A Clin Mol Teratol. 2014;100(5):398.
2. Bakker MK, Jentink J, Vroom F, Van Den Berg PB, De Walle HE, De Jong-Van Den Berg LT. Drug prescription patterns before, during and after pregnancy for long-term, occasional and pregnancy-related drugs in the Netherlands. BJOG. 2006;113:559-68.

3. Jentink J, Loane MA, Dolk H, Barisic I, Garne E, Morris JK, et al. For the EUROCAT Antiepileptic Study Working Group. Valproic acid monotherapy in pregnancy and major congenital malformations. N Engl J Med. 2010;362:2185-93.

4. EUROCAT. What is EUROCAT? http://www.eurocat-network. eu/aboutus/whatiseurocat/whatiseurocat. Accessed 16 Oct 2014.

5. Greenlees R, Neville A, Addor MC, Amar E, Arriola L, Bakker $\mathrm{M}$, et al. Paper 6: EUROCAT member registries: organization and activities. Birth Defects Res A Clin Mol Teratol. 2011;91(Suppl 1):S51-100.

6. Dolk H. EUROCAT: 25 years of European surveillance of congenital anomalies. Arch Dis Child Fetal Neonatal Ed. 2005;90:F355-8.

7. de Jonge L, Bakker MK. EUROCAT special report: sources of information on medication use in pregnancy. 2014. http://www. eurocat-network.eu/content/Special-Report-Medication-Use-InPregnancy.pdf. Accessed 12 June 2015.

8. de Jonge L, Zetstra-van der Woude PA, Bos HJ, de Jong-van den Berg LT, Bakker MK. Identifying associations between maternal medicine use and birth defects using a case-population approach: an exploratory study on signal detection. Drug Saf. 2013;36:1069-78.

9. Li DK, Yang C, Andrade S, Tavares V, Ferber JR. Maternal exposure to angiotensin converting enzyme inhibitors in the first trimester and risk of malformations in offspring: a retrospective cohort study. BMJ. 2011;18:343.

10. Ban L, West J, Gibson JE, Fiaschi L, Sokal R, Doyle P, et al. First trimester exposure to anxiolytic and hypnotic drugs and the risks of major congenital anomalies: a United Kingdom populationbased cohort study. PloS One. 2014;25:e100996.

11. Grzeskowiak LE, Gilbert AL, Morrison JL. Exposed or not exposed? Exploring exposure classification in studies using administrative data to investigate outcomes following medicine use during pregnancy. Eur J Clin Pharmacol. 2012;68:459-67.

12. WHO Collaborating Centre for Drug Statistics Methodology. ATC/DDD index 2015. http://www.whocc.no/atc_ddd_index/. Accessed 19 Dec 2013.

13. EUROmediCAT. http://euromedicat.eu/. Accessed 19 Nov 2014.

14. Ford DV, Jones KH, Verplancke JP, Lyons RA, John G, Brown $\mathrm{G}$, et al. The SAIL Databank: building a national architecture for e-health research and evaluation. BMC Health Serv Res. 2009;9:157.

15. Lyons R, Jones K, John G, Brooks C, Verplancke J-P, Ford D, et al. The SAIL Databank: linking multiple health and social care datasets. BMC Med Inform Decis Mak. 2009;9:3.

16. Espnes MG, Bjørge T, Engeland A. Comparison of recorded medication use in the Medical Birth Registry of Norway with prescribed medicines registered in the Norwegian Prescription Database. Pharmacoepidemiol Drug Saf. 2011;20:243-8.

17. Furu K, Wettermark B, Andersen M, Martikainen JE, Almarsdottir AB, Sørensen HT. The Nordic countries as a cohort for pharmacoepidemiological research. Basic Clin Pharmacol Toxicol. 2010;106:86-94.

18. Thygesen LC, Daasnes C, Thaulow I, Brønnum-Hansen H. Introduction to Danish (nationwide) registers on health and social issues: structure, access, legislation, and archiving. Scand J Public Health. 2011;39(7 suppl):12-6.

19. Gagne JJ, Maio V, Berghella V, Louis DZ, Gonnella JS. Prescription drug use during pregnancy: a population-based study in Regione Emilia-Romagna, Italy. Eur J Clin Pharmacol. 2008;64:1125-32. 
20. Coloma PM, Trifirò G, Schuemie MJ, Gini R, Herings R, Hippisley-Cox J, et al. EU-ADR Consortium. Electronic healthcare databases for active drug safety surveillance: is there enough leverage? Pharmacoepidemiol Drug Saf. 2012;21:611-21.

21. EUROCAT. EUROCAT guide 1.3 and reference documents. Instructions for the registration and surveillance of congenital anomalies. 2005. http://www.eurocat-network.eu/content/ EUROCAT-Guide-1.3.pdf. Accessed 20 Dec 2014.

22. Charlton R, Neville A, Jordan S, Pierini A, Damase-Michel C, Klungsøyr K, et al. Healthcare databases in Europe for studying medicine use and safety during pregnancy. Pharmacoepidemiol Drug Saf. 2014;23:586-94.

23. Charlton RA, Jordan S, Pierini A, Garne E, Neville AJ, Hansen $\mathrm{AV}$, et al. Selective serotonin reuptake inhibitor prescribing before, during and after pregnancy: a population-based study in six European regions. BJOG. 2015;122:1010-2.

24. Curtis LH, Weiner MG, Boudreau DM, Cooper WO, Daniel GW, Nair VP, et al. Design considerations, architecture, and use of the Mini-Sentinel distributed data system. Pharmacoepidemiol Drug Saf. 2012;21:23-31.
25. EUROmediCAT. WP3 protocol for prescription data linkage. http://www.euromedicat.eu/content/Protocol\%20data\% 20linkage\%202012-6.pdf. Accessed 4 Mar 2015.

26. de Jonge L, Bos HJ, van Langen IM, de Jong-van den Berg LT, Bakker MK. Antibiotics prescribed before, during and after pregnancy in the Netherlands: a medicine utilization study. Pharmacoepidemiol Drug Saf. 2014;23:60-8.

27. de Jonge L, de Walle HE, de Jong-van den Berg LT, van Langen IM, Bakker MK. Actual use of medications prescribed during pregnancy: a cross-sectional study using data from a populationbased congenital anomaly registry. Drug Saf. doi:10.1007/ s40264-015-0302-z (Epub 2015 Jun 4).

28. Colvin L, Slack-Smith L, Stanley FJ, Bower C. Pharmacovigilance in pregnancy using population-based linked datasets. Pharmacoepidemiol Drug Saf. 2009;18:211-25.

29. Colvin L, Slack-Smith L, Stanley FJ, Bower C. Linking a pharmaceutical claims database with a birth defects registry to investigate birth defect rates of suspected teratogens. Pharmacoepidemiol Drug Saf. 2010;19:1137-50. 